\title{
AWARENESS AND ADHERENCE TO BLOOD BORNE INFECTIONS AMONG SURGEONS.
}

1. MBBS, FCPS, FRCS

Associate Professor Surgery

Fatima Jinnah Dental College, Karachi.

2. MBBS, M.Phil

Assistant Professor Physiology $\mathrm{CMH}$ Institute of Medical Sciences, Bahawalpur.

3. MBBS, FCPS

Associate Professor Surgery Sir Syed College of Medical Sciences, Karachi.

4. MBBS, FRCS Associate Professor Otolaryngology and Infection Control Bahria International Hospital, Karachi.

Correspondence Address:

Dr. Sara Sadiq

H.No: 2146/81, Kamora Colony

Nawabshah.

dr.sarabhatti@gmail.com

Article received on: 19/12/2019

Accepted for publication: 04/03/2020

\begin{abstract}
Amtullah Sheikh1, Sara Sadiq ${ }^{2}$, Fareya Usmani ${ }^{3}$, Salman Baig ${ }^{4}$
ABSTRACT... Objectives: The aim of current study is to document the awareness and how much health care personnel remain adherent to the precautionary measures against blood borne infections during surgical procedures in their respective fields. Study Design: Descriptive Cross Sectional study. Setting: Surgical and Allied Department of various Government and Private Hospitals of Karachi. Material \& Methods: The questionnaire was self-designed and self-explanatory, having Cronbach's-alpha score of 0.72 . Multi-stage random sampling technique was used. Statistical analysis was done by using SPSS version 22. Result: Majority of female doctors $67.2 \%$, were participated in the study while looking over the departments, $41 \%$ were from surgical department while $22.4 \%$ from gynae and obstetrics. Out of the 134 doctors $64.2 \%$ of the doctors had needle prick during some time in their career. Considering specifically the protective measures taken by doctors against BBI, about $23.9 \%$ preferred only double gloving. Looking over the vaccination history, majority of the doctors about $97 \%$ had vaccinated themselves against Hepatitis B and $87.3 \%$ had also tested for HbsAg and Anti HCV. Following prick injury $54.5 \%$ of the doctors had their $\mathrm{HbsAg}$ antibody titer checked and $33 \%$ had the viral markers checked. Conclusion: Blood born infections are not very uncommon in surgical procedures. Current study concluded that doctors are not adopting the preventive measures including use of gowns, double gloves, protective eye-wear and safe handling of sharp instruments during surgery.
\end{abstract}

Key words: Blood Borne Infections, Needle Prick Injury, Protective Measures.

Article Citation: Sheikh A, Sadiq S, Usmani F, Baig S. Awareness and adherence to blood borne infections among surgeons. Professional Med J 2020; 27(8):16641668. DOI: 10.29309/TPMJ/2020.27.08.4431

\section{INTRODUCTION}

Risk of transmission of blood borne infections (BBI) including HIV, Hepatitis B and Hepatitis C virus, are becoming the main matter of concern. Transmission of HBV, HCV \& HIV has been reported from hospital care personnel to patient and from patient to hospital care personnel and from patient to patient. ${ }^{1}$ Although all three are blood borne, the epidemiology of transmission of each differs based on the virus involved. HBV is more effectively transmitted then HCV \& HIV, especially if the source is positive for hepatitis B-e-Antigen (HBeAg) a marker for increased infectivity. In fact, when $\mathrm{HBeAg}$ is present $\mathrm{HBV}$ is on an average 100 times more likely to be transmitted then HIV from infected blood. HCV while less infectious than $\mathrm{HBV}$, is on an average 6 times more likely than HIV following percutaneous exposure..$^{2,3}$
According to centers for disease control and prevention approximately 384,000 percutaneous injuries occur annually in US hospitals with about 236,000 from needle sticks involving hollow bore needles. ${ }^{4} \mathrm{~A}$ recent report shows that the incidence of HIV infection is increasing day by day which is a major contributing risk when these patient undergo into any surgical procedure. ${ }^{5,6}$ Considering specifically the surgeons, high prevalence of $\mathrm{BBI}$ has been reported $^{7}$, the reason behind might be the percutaneous injuries that's account for about $21 \%$ while the other most common underlying reason is glove perforation involving $11.5 \%$ up to $51 \%$ of surgical procedures. $^{8,9}$

Because of high prevalence of $\mathrm{BBI}$, there is a need of evaluation of working environment, patient's condition and operating procedure which can 
contribute to the transmission of BBI. The Code of Practice suggests multiple safety factors to adapt for preventing risk of $\mathrm{BBI}$ either to health care personnel or from equipment to patient. Precautionary measures including use of gowns, double gloves, eye protection and safe handling of sharp instruments are recommended. ${ }^{10,11}$ In Pakistan no data is available so the aim of this study is to document the awareness and how much health care personnel remain adherent to the precautionary measures against blood borne infections during surgical procedures in their respective fields.

\section{MATERIAL \& METHODS}

A descriptive cross-sectional study was conducted among consultants, resident, house officers and internees from surgery and allied department of various government and private hospitals of Karachi. The survey was conducted from February 2019 to April 2019. A questionnaire was formulated regarding the awareness and adherence to blood borne infections, their vaccination status, preventive measures taken during surgical procedures by them and measures taken by them in case of prick injury. The questionnaire was self-designed and selfexplanatory, having Cronbach's-alpha score of 0.72 . Multi-stage random sampling technique was used, during first stage government and private hospitals were randomly selected then doctors were selected randomly from surgical and allied departments. A total of 134 doctors were enrolled in the study. The study got approval from the ethical review committee, beside this informed written consent was taken from the participants. Statistical analysis was done by using SPSS software version 22. Frequencies along with percentage were calculated for each variable.

\section{RESULTS}

A total of 134 doctors were included in this study. The response rate was $98 \%$. Majority of female doctors $67.2 \%$, were participated in the study while only $32.8 \%$ were male doctors. Looking over the departments, majority of $41 \%$ were from surgical department while $22.4 \%$ from gynae and obstetrics as presented in Figure-1. About 49.6\% doctors, who participated in the survey were post- graduates, $28.5 \%$ were consultants, $16.1 \%$ were house officers while $3.6 \%$ were interns. Out of the 134 doctors $64.2 \%$ of the doctors had needle prick during some time in their career.

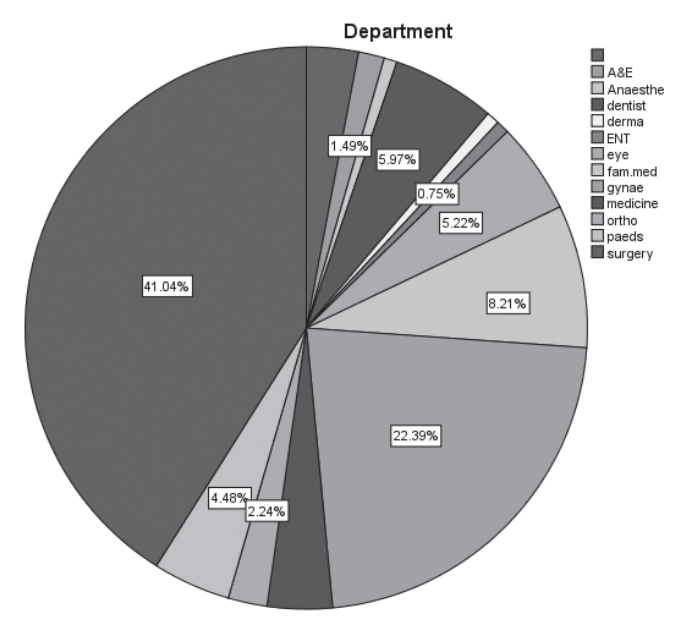

Figure-1. Surgical and allied departments involved in the study.

Considering specifically the protective measures taken by doctors against $\mathrm{BBI}$, about $23.9 \%$ preferred only double gloving while $19.4 \%$ did hand wash along with double gloving but for $17.2 \%$ hand washing was enough as presented in Figure-2.

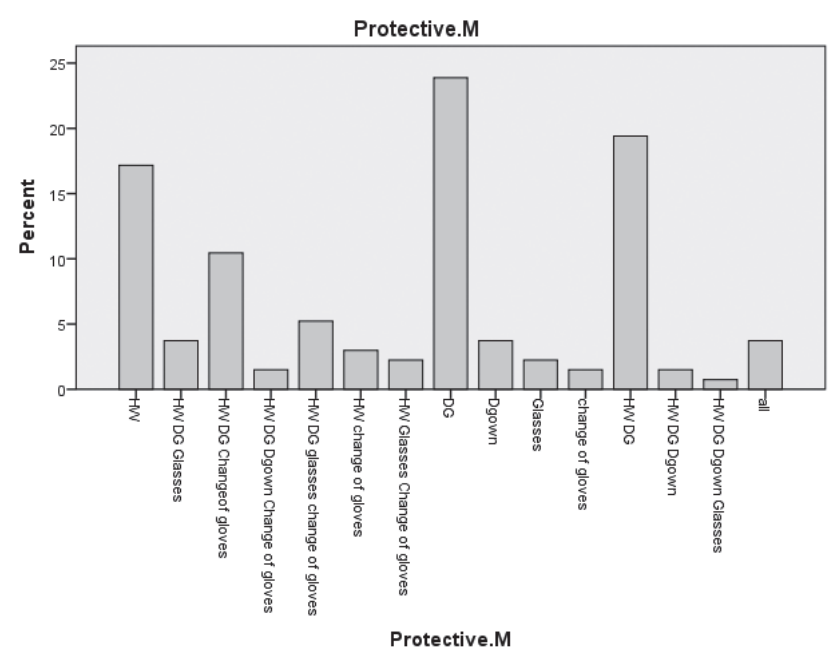

Figure-2. Protective measures taken by doctors during surgical procedure.

Looking over the vaccination history, majority of the doctors about $97 \%$ had vaccinated themselves against Hepatitis B and $87.3 \%$ had 
also tested for HbsAg and Anti HCV. Only 65.7\% tested the patients for HBV \& HCV before any minor procedure Following prick injury 54.5\% of the doctors had their HbsAg antibody titer checked and 33\% had the viral markers checked as reported in Table-l.

\begin{tabular}{|l|c|c|}
\hline \multicolumn{2}{|c|}{ Yes } & No \\
\hline $\begin{array}{l}\text { Vaccination status of } \\
\text { doctors against Hepatitis B }\end{array}$ & 130 \{97\%) & $4(3 \%)$ \\
\hline $\begin{array}{l}\text { Tested for HbsAg \& Anti } \\
\text { HCV }\end{array}$ & $117(87.3 \%)$ & $17(12.7 \%)$ \\
\hline $\begin{array}{l}\text { Tested patient for HBV \& } \\
\text { HCV before procedure }\end{array}$ & $88(65.7 \%)$ & $46(34.3 \%)$ \\
\hline Measures taken after prick injury & $45(33.6 \%)$ & $89(66.4 \%)$ \\
\hline Viral markers testing & $73(54.5 \%)$ & $61(45.5 \%)$ \\
\hline $\begin{array}{l}\text { HbsAg antibody titer } \\
\text { Table-I. Viral marker testing and vaccination history. }\end{array}$ \\
\hline
\end{tabular}

\section{DISCUSSION}

Current surgical practice can expose the surgeon to unnecessary risk of infection. As there is multiple recommended preventive measure for health care personnel including use of gowns, gloves, eye protection and safe handling of sharp instruments but still the incidence of $\mathrm{BBI}$ is higher among surgeons due to their negligence. Like gloves act as a barrier for transmission of infection between surgeon and patients, as surgeons are in contact with body fluids and viscera, but literature reported higher incidence of glove perforation during different surgical procedures, average of about $35 \%$ in minor procedures while up to $54 \%$ in major surgeries. ${ }^{12,13}$ This can be reduced by the use of double gloves as the studies reported a wide variation for the perforation of double gloves, consisting of $0-30 \%$ of perforation risk. These variation is because of type of surgery as the double glove perforation risk is $0 \%$ in vascular surgery while $30 \%$ in joint arthroplasty but very few gynecologists prefer to use double gloves. Literature review revealed that $38 \%$ of surgeons with single glove had blood on their hands and the rate reduced up to $2 \%$ among surgeons with double gloves, this highlights the importance of double gloves., 92,14 Looking over the current study only $23.9 \%$ preferred double gloving, $19.4 \%$ did hand wash along with double gloving but for $17.2 \%$ hand washing was enough. This because of lack of resources and increase number of patients which enforces doctor to put his/her care aside.

Beside needle-stick injury the second major route of $\mathrm{BBI}$ transmission is muco-cutaneous exposure including blood-splashes into eye. Literature reported a high incidence of ocular eye-splashes of about $45 \%$ to $62 \%$. This can be preventable by wearing protective eye-wear including surgical goggles or mask with visors. ${ }^{15,16}$ The current study reported that the use of surgical goggles is not fully adopted by the surgeons that might be due to the two reasons either lack of availability or surgeon's discomfort.

Infection control recommendations must be adhered rigorously to minimized the risk of exposure to BBI. Measures such a use of gowns, double gloves, protective eye-wear and safe handling of sharp instruments should be taken. Hands should be cleaned with alcohol-based hand rub or washed with either plain or antimicrobial soap before and immediately after each patient encounter. Gloves are not a substitute for hand washing. In addition to gloves, protective eye cover, masks, gown and shoe covers may be worn as necessary while performing procedures. No touch suturing technique should be used whenever possible. ${ }^{11}$ Follow-up testing should be conducted at 6 weeks, 3 months and 6 months for known HIV positive cases. Extended HIV follow-up (E.g. for 12 months) is recommended for HCP, who have become infected with HCV. A contaminated area should be washed immediately with soap and water. If skin is cut or punctured, gloves should be removed and wound washed with soap and water. Serological testing should be done. After exposure to HBV immuneprophylactic treatment (hepatitis b vaccine) can prevent infection. Currently no vaccine or post exposure prophylaxis is available for $\mathrm{HCV}^{17}$

\section{CONCLUSION}

Blood born infections are not very uncommon in surgical procedures. Current study concluded that doctors are not adopting the preventive measures including use of gowns, double gloves, 
protective eye-wear and safe handling of sharp instruments during surgery. So majority had needle prick injury during their career, among them very few had viral markers and hepatitis $B$ surface antigen antibody titer check after the prick. It is important that all doctors should be aware about the preventive measure and hospitals should adopt and strictly follow a policy to avoid such risk exposure. Patients should be tested for HBV, HCV and HIV before any surgical procedure and all doctors and surgical staff should take measures to protect themselves against blood born infections.

Copyright@ 04 Mar, 2020.

\section{REFERENCES}

1. Priya NL, Krishnan KU, Jayalakshmi G, Vasanthi S. An analysis of multimodal occupational exposure leading to blood borne infections among health care workers. Indian Journal of Pathology and Microbiology. 2015; 58(1):66.

2. Jaffray CE, Flint LM. Blood-borne viral diseases and the surgeon. Current problems in surgery. 2003; 40(4):204-51.

3. Beltrami EM, Williams IT, Shapiro CN, Chamberland ME. Risk and management of blood-borne infections in health care workers. Clinical microbiology reviews. 2000; 13(3):385-407.

4. Wilburn SQ, Eijkemans G. Preventing needle stick injuries among healthcare workers: a WHO-ICN collaboration. International journal of occupational and environmental health. 2004; 10(4):451-6.

5. HIV/AIDS JUNPo. Global HIV \& AIDS statistics-2018 fact sheet. UNAIDS org. 2018.

6. Madan A, McKinell K, Posner S, Gaines C, Flint L. Higher risk of HIV transmission during trauma resuscitations. The Journal of the Louisiana State Medical Society: Official organ of the Louisiana State Medical Society. 2000; 152(11):567-71.

7. Ippolito G. Scalpel injury and HIV infection in a surgeon. The Lancet. 1996; 347(9007):1042.
8. Ersozlu S, Akkaya T, Ozgur AF, Tandogan RN. Glove punctures in major and minor orthopaedic surgery with double gloves. InOrthopaedic Proceedings 2009 May (Vol. 91, No. SUPP II, pp. 299-299). The British 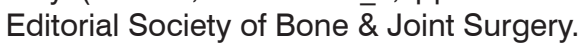

9. Murta EF, Silva CS, Júnior OR. Frequency of glove perforation and the protective effect of double gloves in gynecological surgery. Archives of gynecology and obstetrics. 2003; 268(2):82-4.

10. Popalyar A, Stafford J, Ogunremi T, Dunn K. Challenges in infection control: Infection prevention in personal services settings: Evidence, gaps and the way forward. Canada Communicable Disease Report. 2019; 45(1):1.

11. Cleary S, Doucette K, Doig CJ, Coffin C, Grant D, Dixon E. Canadian association of general surgeons position statement: Recommendations for surgeons with blood-borne communicable diseases. Canadian Journal of Surgery. 2016; 59(2):83.

12. Naver LP, Gottrup F. Incidence of glove perforations in gastrointestinal surgery and the protective effect of double gloves: a prospective, randomized controlled study. European Journal of Surgery. 2000; 166(4):2935 .

13. Malhotra M, Sharma JB, Wadhwa L, Arora R. Prospective study of glove perforation in obstetrical and gynecological operations: Are we safe enough? Journal of Obstetrics and Gynaecology Research. 2004; $30(4): 319-22$

14. Yinusa W, Li Y, Chow W, Ho W, Leong J. Glove punctures in orthopaedic surgery. International orthopaedics. $2004 ; 28(1): 36-9$.

15. Aisien AO, otobo Ujah IA. Risk of blood splashes to masks and goggles during cesarean section. Medical Science Monitor. 2006; 12(2):CR94-CR7.

16. De Silva R, Mall A, Panieri E, Stupart D, Kahn D. Risk of blood splashes to the eye during surgery. South African Journal of Surgery. 2009; 47(1).

17. Lee JM, Botteman MF, Xanthakos N, Nicklasson L. Needlestick injuries in the United States: Epidemiologic, economic, and quality of life issues. Aaohn Journal. 2005; 53(3):117-33. 


\begin{tabular}{|c|c|c|c|}
\hline \multicolumn{4}{|c|}{ AUTHORSHIP AND CONTRIBUTION DECLARATION } \\
\hline Sr. \# & Author(s) Full Name & Contribution to the paper & Author(s) Signature \\
\hline 2 & $\begin{array}{l}\text { Amtullah Sheikh } \\
\text { Sara Sadiq } \\
\text { Fareva Usmani }\end{array}$ & $\begin{array}{l}\text { Conceived \& designed the } \\
\text { study, conducted research. } \\
\text { Wrote initial \& final draft \& } \\
\text { article. } \\
\text { Collected \& organized data. }\end{array}$ & \\
\hline 4 & Salman Baig & & \\
\hline
\end{tabular}

